\title{
Vitamin K deficiency: a case report and review of current guidelines
}

\author{
Maria Rosaria Marchili ${ }^{1 *}$, Elisa Santoro ${ }^{2}$, Alessandra Marchesi ${ }^{1}$, Simona Bianchi ${ }^{1}$, Lelia Rotondi Aufiero ${ }^{1}$ and \\ Alberto Villani ${ }^{1}$
}

\begin{abstract}
Background: Vitamin K, a fat soluble vitamin, is a necessary cofactor for the activation of coagulation factors II, VII, IX, $\mathrm{X}$, and protein $\mathrm{C}$ and $\mathrm{S}$. In neonatal period, vitamin K deficiency may lead to Vitamin K Deficiency Bleeding (VKDB).

Case presentation: We present the case of a 2 months and 20 days Caucasian male, presented for bleeding from the injections sites of vaccines. At birth oral vitamin K prophylaxis was administered. Neonatal period was normal. He was exclusively breastfed and received a daily oral supplementation with $25 \mu \mathrm{g}$ of vitamin $\mathrm{K}$. A late onset vitamin K deficiency bleeding was suspected. Intravenous Vitamin K was administered with complete recovery.
\end{abstract}

Conclusions: Nevertheless the oral prophylaxis, our case developed a VKDB: it is necessary to revise the current guidelines in order to standardize timing and dosage in different clinical conditions.

Keywords: Vitamin K, Deficiency, Bleeding, Breastfeeding, Case report

\section{Background}

Vitamin K, a fat soluble vitamin, is a necessary cofactor for the activation of coagulation factors II, VII, IX, X, and protein $\mathrm{C}$ and $\mathrm{S}$. Vitamin $\mathrm{K}$ deficiency may lead to Vitamin K Deficiency Bleeding (VKDB). The VKDB is a disorder of hemostasis in which coagulation parameters are quickly corrected by vitamin $\mathrm{K}$ supplementation. The term VKDB replaced the wording of hemorrhagic disease of the newborn since vitamin K deficiency bleeding may also occur in the postnatal period.

The diagnosis is suggested by an International Normalized Ratio (INR) $\geq 4$ or a Prothrombin Time (PT) greater than 4 times the normal values, in the presence of a normal platelet count and normal fibrinogen level. Diagnosis confirmation requires vitamin K-dependent factors dosage, which levels are quickly corrected by parenteral administration of $1 \mathrm{mg}$ of vitamin $\mathrm{K}$ [1].

There are different forms of VKDB: early, classic and late.

Early form occurs within the first $24 \mathrm{~h}$ of life in infants born from mothers treated during pregnancy with anticonvulsants (carbamazepine, phenytoin and barbiturates),

\footnotetext{
* Correspondence: mrosaria.marchili@opbg.net

${ }^{1}$ Pediatric and Infectious Disease Unit, Bambino Gesu' Children's Hospital,

IRCCS, Piazza Sant'Onofrio 4, Rome, Italy

Full list of author information is available at the end of the article
}

antituberculosis drugs (isoniazid, rifampicin), some antibiotics (cephalosporins) or vitamin $\mathrm{K}$ antagonists (warfarin) and who did not received vitamin $\mathrm{K}$ prophylaxis before the delivery [1]. It incidence in at-risk neonates without vitamin $\mathrm{K}$ supplementation varies from $6 \%$ to $12 \%$. The classic form occurs between $24 \mathrm{~h}$ to 7 days of life and is more often idiopathic; in term born not receiving vitamin $\mathrm{K}$ prophylaxis it presents an incidence of $0,25-1,5 \%$ in older reviews [2] and $0,01-0,44 \%$ in more recent reviews [3]. The classic form is related to the low placental transfer of vitamin $\mathrm{K}$, low concentration in breast milk, lack of gastrointestinal flora in the newborn gut, and poor oral intake that commonly occurs in the newborn period as breastfeeding is initiated. The late form occurs between the 2nd week and the 6th month of life, with a peak between 3 and 8 weeks after birth; it has an incidence of 1/15.000-1/ 20.000 births and it is typical of exclusive breastfed infants or newborns with malabsorption or cholestasis because vitamin $\mathrm{K}$ absorption is closely dependent on the intestinal availability of bile. The hemorrhagic manifestations mainly involve gastrointestinal tract and skin, but also the central nervous system in late forms $[4,5]$. Late VKDB carries a significant morbidity and mortality rate, with a mortality as high as $20-50 \%$ and a morbidity characterized by neurologic defects including hydrocephalus, cerebral atrophy, encephalopathy, epilepsy, and developmental delay [6]. 
Breastfeeding has been implicated as risk factor for the development of VKDB because human milk vitamin $\mathrm{K}$ concentration (median $2.5 \mathrm{mg} / \mathrm{L}$ [0.85-9.2 $\mathrm{mg} / \mathrm{L}]$ ) is significantly lower than currently available formula milk (4-25 mg/ $100 \mathrm{kcal}$ approximately corresponding to $24-175 \mathrm{mg} / \mathrm{L}$ ) [7, 8]. On average daily vitamin $\mathrm{K}$ intake of breastfed infants is $<1 \mathrm{mg}$ within the first 6 months of life, whereas the intake of formula-fed infants is on average up to 100 times higher [9].

Vitamin K deficiency leads to the synthesis of undercarboxylated proteins called PIVKA (protein induced by vitamin $\mathrm{K}$ absence), that are unable to bind calcium and therefore inactive. PIVKAs are released from the liver into the blood and their level increases with the severity of the deficiency. PIVKAs are, however, much more commonly reported in breastfed infants [10].

\section{Case presentation}

We reported the case of a 2 months and 20 days white Caucasian male, presented for bleeding from the injections sites of the first dose of hexavalent and pneumococcal vaccine.

He was born from unrelated parents at 41 weeks of gestational age by urgent cesarean section, with a birth weight of $3200 \mathrm{~kg}$ and a 5-min Apgar score of 10. His mother reported no use of drug during pregnancy and a previous miscarriage. At birth oral vitamin K prophylaxis was administered. Neonatal period was normal. He was exclusively breastfed and he received a daily supplementation of $25 \mu \mathrm{g}$ of vitamin $\mathrm{K}$ and $400 \mathrm{IU}$ of vitamin D.

At admission he was in fairly good general conditions, he was awake and responsive, with a valid crying and age-appropriate neurological findings. On the anterior region of both thighs, the injection sites of vaccines were recognizable, with a slight bleeding from the injection site on the left leg, without signs of edema. He had a normal cardiorespiratory activity and normal vital signs (blood pressure 70/46 $\mathrm{mmHg}$, heart rate $126 \mathrm{bpm}$, respiratory rate 30 acts $/ \mathrm{min}$, body temperature $36{ }^{\circ} \mathrm{C}$ ).

Blood tests showed a progressive anemia with a minimum value of hemoglobin of $7.8 \mathrm{~g} / \mathrm{dl}$ (laboratory findings are shown in Table 1). The dosage of coagulation factors showed low values of the vitamin-K dependent factors (factor II 2\%, factor VII 4\%, factor IX 2\%, factor X 5\%) and normal values of factor $\mathrm{V}(128 \%)$. Abdominal and brain ultrasound excluded an ongoing bleeding. Fecal elastase on three samples and serology for HIV, HCV, HBV, CMV, EBV, HHV-6, Parvovirus B19 were negative (except for positive IgG for CMV).

Based on the clinical history and laboratory findings, a vitamin K deficiency bleeding "late onset" was suspected. Intravenous Vitamin K (Konakion $10 \mathrm{mg}$ ) was administered together with a continuous infusion of $1 \mathrm{~g}$ of tranexamic acid. Considering the low hemoglobin values, he was transfused without any adverse reaction.
Table 1 laboratory findings at admission

\begin{tabular}{|c|c|c|}
\hline \multirow[t]{2}{*}{ Test } & \multicolumn{2}{|l|}{ Result } \\
\hline & At admission & At discharge \\
\hline $\mathrm{Hb}$ & $7,8 \mathrm{~g} / \mathrm{dl}$ & $9,8 \mathrm{~g} / \mathrm{dl}$ \\
\hline PLT & 152.000/uL & $328.000 / \mathrm{uL}$ \\
\hline INR & Not measurable & 0,94 \\
\hline PT & $>100 \mathrm{~s}($ n.v. $11,5-15,3)$ & 12,4 (n.v. $11,5-15,3$ ) \\
\hline aPTTs & 166,9 s (n.v. 26-50) & 28,5 (n.v. 26-50) \\
\hline aPPTr & 5,72 (n.v. 0,88-1,69) & 0,98 (n.v. 0,88-1,69) \\
\hline Antithrombin III & 126\% (n.v. 32-72) & / \\
\hline Fibrinogen & 467 mg/dl (n.v. 200-500) & 414 (n.v. 200-500) \\
\hline Factor \| & 2\% (n.v. 30-60) & / \\
\hline Factor VII & 4\% (n.v. 40-72) & / \\
\hline Factor IX & 2\% (n.v. 20-36) & / \\
\hline Factor X & 5\% (n.v. 40-72) & / \\
\hline Factor V & 128\% (n.v. 70-120) & / \\
\hline AST & 78 UI/L (n.v. 5-40) & 69 UI/L (n.v. 5-40) \\
\hline ALT & 41 UI/L (n.v. 5-40) & 40 UI/L (n.v. 5-40) \\
\hline
\end{tabular}

N.v. normal values, $H b$ hemoglobin, PLT platelets, INR International normalized ratio, PT Prothrombin Time, aPTT Activated partial thromboplastin time, AST Aspartate-aminotransferase, $A L T$ alanine-aminotransferase

After vitamin $\mathrm{K}$ administration a normalization of the coagulation parameters with persistence of anemia $(\mathrm{Hb}$ $8.8 \mathrm{~g} / \mathrm{dl}$ ) was observed. Treatment was therefore continued with oral vitamin $\mathrm{K}$, and iron and folic acid supplementation.

During hospitalization, he did not presented further bleeding or other symptom. At discharge coagulation parameters were normal (PT 12.4 s, INR 0.94, aPTTs 28.5 s, aPTT-r 0.98, PLT 328,000/ $\mu$ l, fibrinogen $414 \mathrm{mg} /$ $\mathrm{dl}$ ) and hemoglobin values were increased ( $\mathrm{Hb} 9.8 \mathrm{~g} / \mathrm{dl}$ ). The child was discharged with the indication to continue oral vitamin $\mathrm{K}$ supplementation with Konakion $10 \mathrm{mg}$ twice weekly until weaning.

\section{Discussion}

Since 1961 the American Academy of Pediatrics has recommended that all neonates receive a single intramuscular dose of $0.5-1 \mathrm{mg}$ of vitamin $\mathrm{K}$ for the prevention of VKDB [11].

NICE guidelines of 2015 reiterated the recommendation to administer vitamin $\mathrm{K}$ at birth; in particular, they recommended to administer $1 \mathrm{mg}$ of vitamin $\mathrm{K}$ intramuscularly to all newborns in order to prevent VKDB. If intramuscular administration is rejected by parents, the administration of multiple oral doses is recommended. These recommendations are based on the evidence that intramuscular administration of vitamin $\mathrm{K}$ is clinically more effective than oral administration, and that multiple oral doses of Vitamin $\mathrm{K}$ are necessary to obtain adequate protection against the late VKDB onset in breastfed children [12, 13]. 
A Joint Position Statement from the Canadian Paediatric Society and the College of Family Physicians of Canada, published in 1997 and re-affirmed in 2014, recommended that a single intramuscular dose of vitamin K $(0.5 \mathrm{mg}$ for birthweight $\leq 1500 \mathrm{~g}$ or $1.0 \mathrm{mg}$ for birthweight $\geq 1500 \mathrm{~g}$ ) should be administered to all newborns within the first $6 \mathrm{~h}$ after birth. If intramuscular vitamin $\mathrm{K}$ is refused by parents, an oral dose of $2 \mathrm{mg}$ vitamin $\mathrm{K}$ was recommended at the time of first feeding, followed by a second dose at 2 to 4 weeks, and a third dose at 6 to 8 weeks [14]. Similar recommendations are provided by two practice guidelines, one from Perinatal Services British Columbia [15] and one from the Winnipeg Regional Health Authority [16].

In 1992 Golding et al. reported an increased risk of developing childhood cancer after intramuscular vitamin K prophylaxis [17]. Subsequent studies, however, showed no significant correlation between parenteral vitamin $\mathrm{K}$ prophylaxis at birth and development of tumors in childhood $[18,19]$. But since the report of Golding et al. an increasing trend towards oral vitamin $\mathrm{K}$ administration had become.

A single vitamin $\mathrm{K}$ oral dose at birth is efficacy in prevention of classic VKDB, but it does not protect against late VKDB because of the shorter duration of oral vitamin $K$ activity compared to intramuscular administration. In fact studies suggest that after a single oral dose vitamin K levels fall to unsupplemented levels within 2 weeks. Several mechanism can explain the major efficacy of intramuscular vitamin $\mathrm{K}$ administration, including poor absorption after oral administration and depot effect at the site of intramuscular injection [20].

Although it is clear that more than a single oral dose is needed, especially in exclusively breastfed infants, there is no consensus in the literature regarding the best oral vitamin $\mathrm{K}$ regimen to prevent late VKDB. In the absence of evidence there is a heterogeneity in prophylactic strategies, concerning the route of administration and the dosage of vitamin $\mathrm{K}$ used, with differences not only between countries, but also within the same country, as in the case of Italy. So a variety of continuous oral regimens have been studied (Table 2), but clinical trials comparing their efficacy and safety are lacking.

Primarily epidemiological data from several European countries showed that the most effective dosing strategy seems to be a continuous oral prophylaxis with weekly doses of $1 \mathrm{mg}$ (Danish scheme) or daily doses of $25 \mu \mathrm{g}$ (Dutch scheme) for 3 months. In particular, Danish scheme is based on an important study of Hansen et al., published in 2003, which has established that $1 \mathrm{mg}$ of oral vitamin $\mathrm{K}$ given weekly during the first 3 months of life, following an initial oral dose of $2 \mathrm{mg}$ of vitamin $\mathrm{K}$ directly after birth, is as effective as $1 \mathrm{mg}$ of vitamin $\mathrm{K}$ given intramuscularly at birth [21]. Afterwards a surveillance study of 2005, published in 2008, in Netherland evidenced that daily dose of $25 \mu \mathrm{g}$ was not effective in preventing idiopathic late VKDB. For this reason the authors suggested to double the daily dose of vitamin $\mathrm{K}$

Table 2 VKDB prophylaxis strategies in various countries

\begin{tabular}{|c|c|c|c|}
\hline Country & Years Studied & Oral Vitamin K dosing regimen & $\begin{array}{l}\text { Incidence of Late VKDB per 100,000 } \\
\text { Infants }(95 \% \mathrm{Cl})\end{array}$ \\
\hline \multirow[t]{2}{*}{ Netherlands } & 1992-1994 & $1 \mathrm{mg}$ at birth; $25 \mu \mathrm{g}$ daily for 13 wk. & $0(0$ to 0.7$)$ \\
\hline & since 2005 & $1 \mathrm{mg}$ at birth; $25 \mu \mathrm{g}$ daily for 13 wk. & $3.2(1.2$ to 6.9$)$ \\
\hline \multirow[t]{4}{*}{ Germany } & 1993-1994 & $3 \times 1 \mathrm{mg}$ (days 1, 4-10, and 28-42) & $1.3(0.8$ to 2.0$)$ \\
\hline & 1995-1998 & $3 \times 2 \mathrm{mg}$ (days 1, 4-10, and 28-42) & $0.4(0.2$ to 0.7$)$ \\
\hline & $1997-2000$ & $3 \times 2 \mathrm{mg}$ (days 1, 4-10, and 28-42) & $0.8(0.4$ to 1.4$)$ \\
\hline & 1997-2001 & $3 \times 2 \mathrm{mg}$ (days 1, 4-10, and 28-42) & $0.44(0.2$ to 0.9$)$ \\
\hline France & / & 2 mg weekly for 6 mo & no date available \\
\hline Australia & 1993-1994 & $3 \times 1 \mathrm{mg}$ (days 1, 3-5, and 21-28) & $1.5(0.5$ to 3.6$)$ \\
\hline \multirow[t]{2}{*}{ Denmark } & 1992-2000 & $2 \mathrm{mg}$ at birth; $1 \mathrm{mg}$ weekly for 3 mo & $0(0$ to 0.9$)$ \\
\hline & since 2000 & $2 \mathrm{mg}$ im at birth & no date available \\
\hline \multirow[t]{2}{*}{ Switzerland } & $1995-2002$ & $2 \times 2 \mathrm{mg}(\mathrm{h} 4$, day 4) & $1.2(0$ to 6.5$)$ \\
\hline & since 2003 & $3 \times 2$ mg (h 4, day 4, week 4) & 0,87 (0.24 to 2.24) \\
\hline \multirow[t]{2}{*}{ United Kingdom } & / & $\begin{array}{l}1 \mathrm{mg} \mathrm{im} \text { at birth; } 3 \times 1 \mathrm{mg} \text { po (day } 1 \text {, } \\
\text { week } 1 \text {, week } 4 \text { ) }\end{array}$ & 0.1 \\
\hline & / & $3 \times 2$ mg po (day 1, week 1, week 4) & 0.43 \\
\hline Canada & / & $1 \mathrm{mg}$ im at birth & 0.37 \\
\hline United States & / & $1 \mathrm{mg}$ im at birth & no date available \\
\hline Italy & / & various schemes & no date available \\
\hline
\end{tabular}


to $50 \mu \mathrm{g}$ for all breastfed babies from 1 to 13 weeks to prevent bleeding in also infants with underlying cholestatic liver disease [22].

Recently Witt et al. evaluated whether a prophylactic regimen of $1 \mathrm{mg}$ vitamin $\mathrm{K}$ orally at birth followed by $150 \mu$ g daily during weeks 2 to 13 sufficiently prevented VKDB in breastfed infants. Their data in high-risk group, for example undiagnosed children with biliary atresia, showed that this regimen does not successfully prevent VKDB in these children, in contrast to a regimen consisting of a single intramuscular injection of $2 \mathrm{mg}$ vitamin $\mathrm{K}$ at birth. They concluded that a prophylactic regimen for breastfed infants consisting of $1 \mathrm{mg}$ vitamin $\mathrm{K}$ orally at birth, followed by either $25 \mu \mathrm{g}$ or $150 \mu \mathrm{g}$ daily during weeks 2 to 13 , does not sufficiently prevent VKDB in breastfed infants with still undiagnosed biliary atresia. They assumed that this insufficient prevention is also present in infants with yet undiagnosed others forms of neonatal cholestasis. In their study efficient prevention was obtained by regimen consisting of single intramuscular injection of $2 \mathrm{mg}$ vitamin $\mathrm{K}$ at birth [23].

However, cases of VKDB in exclusively breastfed healthy newborns, despite intramuscular prophylaxis at birth, have been described, suggesting that prophylaxis with a single dose of intramuscular vitamin $\mathrm{K}$ may be inadequate to prevent all cases of late VKDB [24-26].

In consideration of these reports, since 2004, the Italian Society of Neonatology recommends an oral administration of vitamin $\mathrm{K}$ in all exclusively breastfed newborns in the period from the 2 nd to 14 th weeks of age [27].

In our clinical case the child had been subjected at birth to oral administration of vitamin $\mathrm{K}$ and, subsequently, to a daily oral supplementation with $25 \mu \mathrm{g}$. Nevertheless, he developed a late-onset VKDB, although he had not cholestatic disease or malabsorption, but exclusively breastfeeding as only risk factor.

The reporting of late-onset VKDB in breastfed children invite us to reflect on the problem of prophylaxis in breastfed infants and the need of reviewing the guidelines and, in particular, the dose of oral supplementation with vitamin $\mathrm{K}$ in children taking only breast milk, considering, in addition, that hat oral supplementation is dependent on the compliance of the parents administering the vitamin in form of drops (with the real risk that the assumed dose is less than the desired dose).

Finally, despite evidence of major efficacy of intramuscular administration in preventing late forms of VKDB, mostly in children with risk factors (breastfeeding, unknown conditions of cholestasis or malabsorption), in the absence of shared guidelines there are still some birth Centers where oral prophylaxis is routinely performed at birth.

\section{Conclusion}

NICE guidelines of 2015 recommend to administer $1 \mathrm{mg}$ of vitamin $\mathrm{K}$ intramuscularly to all newborns in order to prevent VKDB. If intramuscular administration is rejected by parents, the administration of multiple oral doses is recommended as a second option. These recommendations are based on the evidence that intramuscular administration is clinically more effective than oral administration, and that multiple oral doses of vitamin $\mathrm{K}$ are necessary to obtain adequate protection against late onset VKDB in breastfed children $[12,13]$.

Nevertheless the exact dosage and timing of oral administration after the starting dose at birth, are not yet well defined [28]. On the other hand, late-onset VKDB cases have also been reported in children undergoing intramuscular administration of vitamin $\mathrm{K}$ at birth (not followed by subsequent oral supplementation) [24-26].

No data are available regarding the incidence of late onset VKDB after intramuscular prophylaxis at birth followed by oral supplementation [29].

Studies should be performed to evaluate the incidence of late onset VKDB in children who receive prophylaxis with vitamin $\mathrm{K}$ intramuscularly at birth, compared to those who receive it orally, with the same successive regimen of oral supplementation.

On the basis of such results we think that it will be necessary a review of guidelines about VKDB prophylaxis in order to standardize timing and dosage in different clinical conditions.

\section{Abbreviations}

CNS: Central nervous system; INR: International normal ratio; NICE: National Institute for Health and Care Excellence; PIVKA: Protein induced by vitamin K absence; PT: Prothrombin Time; VKDB: Vitamin K deficiency bleeding

\section{Acknowledgements}

No acknowledgements

\section{Funding}

Maria Rosaria Marchili, who wrote the first draft of the manuscript, wasn't given to anyone an grant or other form of payment to produce the manuscript.

\section{Authors' contributions}

MRM: She wrote the manuscript. SB: She collected the clinical and laboratory data. MVG: She reviewed the current guidelines, in order to write the discussion. ES: She collected the bibliography. AV: He reviewed the manuscript. Each author listed on the manuscript has seen and approved the submission of this version of the manuscript and takes full responsibility for the manuscript. MRM, who wrote the manuscript, received no grant nor other form of payment to produce the manuscript. All authors read and approved the final manuscript.

\section{Consent for publication}

Written informed consent was obtained from the patient's parents/legal guardians for publication of this case report and any accompanying images. A copy of the written consent is available for the review by the Editor-in-

Chief of this journal.

Contact author for the form.

Competing interests

The authors declare that they have no competing interests. 


\section{Publisher's Note}

Springer Nature remains neutral with regard to jurisdictional claims in published maps and institutional affiliations.

\section{Author details}

'Pediatric and Infectious Disease Unit, Bambino Gesu' Children's Hospital, IRCCS, Piazza Sant'Onofrio 4, Rome, Italy. ${ }^{2}$ Pediatric Department, University of Tor Vergata, Rome, Italy.

Received: 18 January 2018 Accepted: 25 February 2018

Published online: 14 March 2018

\section{References}

1. Lippi G, Franchini M. Vitamin K in neonates: facts and myths. Blood Transfus. 2011;6:4-9.

2. American Academy of Pediatrics, Committee on Nutrition. Vitamin K compounds and their water soluble analogues: use in therapy and prophylaxis in pediatrics. Pediatrics. 1961;28:501-7.

3. Autret-Leca E, Jonville-Béra AP. Vitamin K in neonates. Pediatr Drugs. 2001;3:1-8

4. Ozdemir MA, Karakukcu M, Per H, et al. Late-type vitamin K deficiency bleeding: experience from 120 patients. Childs Nerv Syst. 2012;28:247-51.

5. American Academy of Pediatrics. Committee on Fetus and Newborn. Controversies concerning vitamin K and the newborn. Pediatrics. 2003;112: 191-2.

6. Misirlioglu ED, Aliefendioglu D, Bademci G, Baydar Z, Kose G, Cakm FN Intracranial hemorrhage due to vita- min k deficiency in infancy: clinical and radiological findings. J Neurosurg Sci. 2009;26(1):18-25.

7. Haroon Y, Shearer MJ, Rahim S, et al. The content of phylloquinone (vitamin K1) in human milk, cows' milk and infant formula foods determined by high-performance liquid chromatography. J Nutr. 1982;112:1105-17.

8. Russell R, Beard JL, Cousins R, et al. Vitamin K. In: IOM, editor. Institute of Medicine (US) panel on micronutrients. Dietary reference intakes for vitamin a, vitamin $\mathrm{K}$, arsenic, boron, chromium, copper, iodine, iron, manganese, molybdenum, nickel, silicon, vanadium, and zinc. Washington, DC: National Academy Press; 2001. p. 162-96.

9. Greer FR. Vitamin K status of lactating mothers and their infants. Acta Paediatr Suppl. 1999:88:95-103.

10. Van Winkle M, De Bruyne R, Van De Velde S, Van Biervliet S. Vitamin K, an update for the paediatrician. Eur J Pediatric. 2009:168:127-34.

11. American Academy of Pediatrics. Committee on Nutrition. Vitamin $\mathrm{K}$ compounds and the water-soluble analougues: use in therapy and pophylaxis in pediatrics. Pediatrics. 1961:28501-507.

12. National Institute for Health and Care Excellence. Postnatal care [Internet]. London: The Institute; 2015. Available from: https://www.nice.org.uk/ guidance/cg37/resources/guidance-postnatal-care-pdf. Cited 1 May 2015. (NICE clinical guideline)

13. Dermott K, Bick D, Norman R, et al. Clinical guidelines and evidence review for post natal care: routine postnatal care of women and their babies [Internet]. London: The National Collaborating Centre for Primary Care and Royal College of General Practitioners; 2006. Available from: https://www. nice.org.uk/guidance/cg37/evidence/cg37-postnatal-care-full-guideline3. Cited 1 May 2015

14. McMillan D, Fetus and Newborn Committee. Routine administration of vitamin $\mathrm{k}$ to newborns position statement. A joint position statement with the College of Family Physicians of Canada [Internet]. Ottawa: Canadian Paediatric Society; 2014.

15. Newborn guideline 13. Newborn nursing care pathway [Internet]. Perinatal Services BC: Vancouver; 2013

16. Women's health program and child Health program: practice guidelines. (Vitamin $\mathrm{K}$ for prevention of vitamin $\mathrm{K}$ deficiency bleeding (VKDB) in newborns [Internet]. Winnpeg: Winnipeg Regional Health Authority; 2014. Available from: http://www.wrha.mb.ca/extranet/eipt/files/EIPT-026-001.pdf

17. Golding J, Greenwood R, Birmingham K, Mott M. Childhood cancer, intramuscular vitamin K, and pethidine given during labour. BMJ. 1992; 305(6849):341-6.

18. Ross JA, Davies SM. Vitamin K prophylaxis and childhood cancer. Med Pediatr Oncol. 2000:34(6):434-7.

19. Mihatsch WA1Braegger CBronsky JCampoy CDomellöf MFewtrell MMis NFHojsak IHulst Jndrio FLapillonne AMlgaard CEmbleton Nvan Goudoever ESPGHAN Committee on Nutrition. Prevention of Vitamin K Deficiency
Bleeding in Newborn Infants: A Position Paper by the ESPGHAN Committee on Nutrition. J Pediatr Gastroenterol Nutr. 2016:63(1):123-9.

20. Ipema HJ. Use of oral vitamin $\mathrm{K}$ for prevention of vitamin $\mathrm{K}$ deficiency bleeding in neonates when injectable vitamin $\mathrm{K}$ is not available. Ann Pharmacother. 2012;46:879-83.

21. Hansen KN, Minousis M, Ebbesen F. Weekly oral vitamin K prophylaxis in Denmark. Acta Paediatr. 2003;92(7):802-5.

22. IJland MM, Pereira RR, Cornelissen EAM. Incidence of late vitamin K deficiency bleeding in newborns in the Netherlands in 2005: evaluation of the current guideline. Euro J Pediatr. 2008;167:165-9.

23. Witt M, Kvist N, Hørby Jørgensen M, Hulscher JBF, Verkade HJ, also, on behalf of the Netherlands Study group of Biliary Atresia Registry (NeSBAR). Prophylactic dosing of vitamin K to prevent bleeding. Pediatrics. 2016; 137(5):e20154222

24. Solves P, Altés A, Ginovart G, Demestre J, Fontcuberta J. Late hemorrhagic disease of the newborn as a cause of intracerebral bleeding. Ann Hematol. 1997;75:65-6. Q Springer-Verlag 1997

25. Latini G, Quartulli L, De Mitri B, Del Vecchio A, Vecchio C. Intracranial hemorrhage associated with vitamin K deficiency in breastfed infant after intramuscolare vitamin K prophylaxis at birth. Follow up at 18 months. Acta Paediatr. 2000;89:878-86

26. Ciantelli M, Bartalena L, Bernardini M, Biver P, Chesi F, Boldrini A, Sigali E. Late vitamin $\mathrm{K}$ deficiency bleeding after intramuscular prophylaxis at birth: a case report. J Perinatol. 2009;29:168-9.

27. Italian Society of Neonatology. Profilassi con la vitamina K nell'emorragia da deficit di vitamina K. Consensus Conference, Siena 2 aprile 2004. 2004.

28. Neonatal Vitamin K Administration for the Prevention of Hemorrhagic Disease: A Review of the Clinical Effectiveness, Comparative Effectiveness, and Guidelines. Canadian agency for drug and technologies in health. 2015

29. Malguzzi S, Col M, Ghitti C, Clavenna A. Prevenzione dell'emorragia tardiva del neonato con vitamina K. Quaderni acp. 2005:12:26-8.

\section{Submit your next manuscript to BioMed Central and we will help you at every step:}

- We accept pre-submission inquiries

- Our selector tool helps you to find the most relevant journal

- We provide round the clock customer support

- Convenient online submission

- Thorough peer review

- Inclusion in PubMed and all major indexing services

- Maximum visibility for your research

Submit your manuscript at www.biomedcentral.com/submit
C) Biomed Central 